Актуальные проблемы нефти и газа • Вып. 4(23) 2018 • http://oilgasjournal.ru

Труды Международной конференции «Дегазация Земли: геология и экология - 2018»

УДК 504.5 .06

DOI 10.29222/ipng.2078-5712.2018-23.art85

ОЦЕНКА ПЕРСПЕКТИВ НЕФТЕГАЗОНОСНОСТИ УЧАСТКОВ БУРЕНИЯ СКВАЖИН НА ШЕЛЬФЕ МОБИЛЬНЫМИ ПРЯМОПОИСКОВЫМИ МЕТОДАМИ

\author{
Левашов С.П. ${ }^{1}$, Самсонов А.И. ${ }^{1}$, Якимчук Н.А. ${ }^{1}$, Корчагин И.Н. ${ }^{2}$, Божежа Д.Н. ${ }^{1}$ \\ 1 - ИППЭГГ; 2 - Институт геофизики им. С.И.Субботина НАНУ \\ E-mail: korchagin.i.n@gmail.com
}

Аннотация Анализируются результаты применения прямопоисковой технологии частотно-резонансной обработки спутниковых снимков для оперативной оценки перспектив нефтегазоносности отдельных структур, а также локальных участков бурения поисковых скважин 7435/12-1 Korpfjell (Баренцево море), «Onisiforos West-1» (Средиземное море), «Полшков-1» и «Рубин-1» (Черное море), 34/8-19 S (проектная, Северное море). Обнаруженные прямопоисковым методом аномальные зоны можно считать проекциями контуров скоплений УВ в разрезе на дневную поверхность. Эта оперативная и дополнительная информация может использоваться для приближенной оценки ресурсов УВ в пределах обследованных участков и структур. Результаты экспериментальных исследований свидетельствуют о целесообразности применения прямопоисковых технологий для локализации оптимальных участков бурения скважин. Повышение показателя успешности бурения может привести к существенному ускорению и оптимизации геологоразведочного процесса на нефть и газ в целом.

Ключевые слова: мобильная технология, аномалия типа залежь, нефть, газ, шельф, прямые поиски, обработка данных Д33, интерпретация.

\title{
OIL AND GAS POTENTIAL ESTIMATION OF WELL SITES ON THE SHELF USING THE DIRECT SEARCH METHODS
}

Levashov S.P. ${ }^{1}$, Samsonov A.I. ${ }^{1}$, Yakimchuk N.A. ${ }^{1}$, Korchagin I.N. ${ }^{2}$, Bozhezha D.N. ${ }^{1}$ 1 - IPPEG; 2 - Geophysical Institute of NUAS

E-mail: korchagin.i.n@gmail.com

Abstract The results of satellite data frequency-resonance processing direct search technology use for oil and gas bearing potential estimation of areas around prospecting wells 7435/12-1 Korpfjell (Barents sea), «Onisiforos West-1» (Mediterranean sea), «Polshkov-1» and «Rubin-1» (Black sea), 34/8-19 S (project, North sea). Anomalies detected with abovementioned method can be thought as projections of deep hydrocarbon accumulations on the Earth surface. This additional operative information can be used for $\mathrm{HC}$ resource estimation on the surveyed 
structures. Successful experiments give evidence of direct search methods implementation expediency for optimal well sites localization. The growth of success in drilling will lead to speeding up and optimizing of oil and gas prospecting in whole.

Keywords: mobile technology, deposit type anomaly, oil, gas, shelf, direct search, Earth remote sensing data processing, interpretation.

\section{Введение}

В поисковом процессе на углеводороды львиная доля финансовых ресурсов и времени идут на бурение скважин, положение которые в пределах перспективных структур закладываются по результатам геофизических (сейсмических, в первую очередь) исследований. На данный момент традиционно используемые в разведочном процессе геофизические методы не являются прямыми методами поисков нефти и газа. В связи с этим, коэффициент успешности бурения невысокий - многие поисковые скважины оказываются сухими или же не дают коммерческих притоков УВ. Вполне понятно, что повышение коэффициента успешности бурения скважин даже в два раза может привести к существенному сокращению финансовых затрат, а также времени на проведение поисково-разведочных работ на нефть и газ. В статье приводятся результаты оценки перспектив нефтегазоносности локальных участков бурения поисковых скважин в Баренцевом, Средиземном, Черном и Северном морях частотно-резонансным методом обработки и декодирования спутниковых снимков. Авторы надеются, что такая демонстрация потенциальных возможностей мобильного прямопоискового метода для повышения успешности бурения скважин будет способствовать более активному применению такого рода технологий (прямопоисковых) в геологоразведочном процессе на нефть и газ.

\section{Методы исследований}

Использовалась технология частотно-резонансной обработки и интерпретации данных дистанционного зондирования Земли (ДЗ3) с целью прямых поисков и разведки скоплений горючих и рудных полезных ископаемых - нефти, газа, газоконденсата, воды, золота, урана, и т.д. [2-5]. В рамках технологии дополнительно разработан и активно используется специальный метод оценки максимальных значений пластовых давлений флюидов в коллекторах [3]. Полученные оценки максимальных значений пластового 
Труды Международной конференции «Дегазация Земли: геология и экология - 2018»

давления дают возможность оценить в первом приближении глубины залегания, перспективных на обнаружение УВ горизонтов (объектов).

\section{Скважина 7435/12-1 Korpfjell в Баренцевом море}

В 2014 г. в норвежской части бывшей «серой» зоны Баренцева моря в пределах четырех участков проведены сейсмические исследования 3Д. В этом же году авторами выполнена оценка перспектив нефтегазоносности этих участков с использованием частотно-резонансного метода обработки и интерпретации данных ДЗ3 [6].

В январе 2018 г. в Интернете была обнаружена информация, что в пределах четвертого участка проведения сейсмических работ на перспективной структуре была пробурена скважина 7435/12-1 Korpfjell глубиной 1508 м (рис. 1); в скважине обнаружена залежь газа, которую на данный момент разрабатывать невыгодно. Отмечается также, что испытание обнаруженных в скважине коллекторов на притоки газа не проводилось.

Обратим внимание на то, что в мелком масштабе (1:400000) обработки спутникового снимка четвертого участка (рис. 1) на обследованной площади обнаружена только одна аномальная зона типа «газ+конденсат» в северной части площади. В районе расположения пробуренной скважины аномальные зоны не зафиксированы.

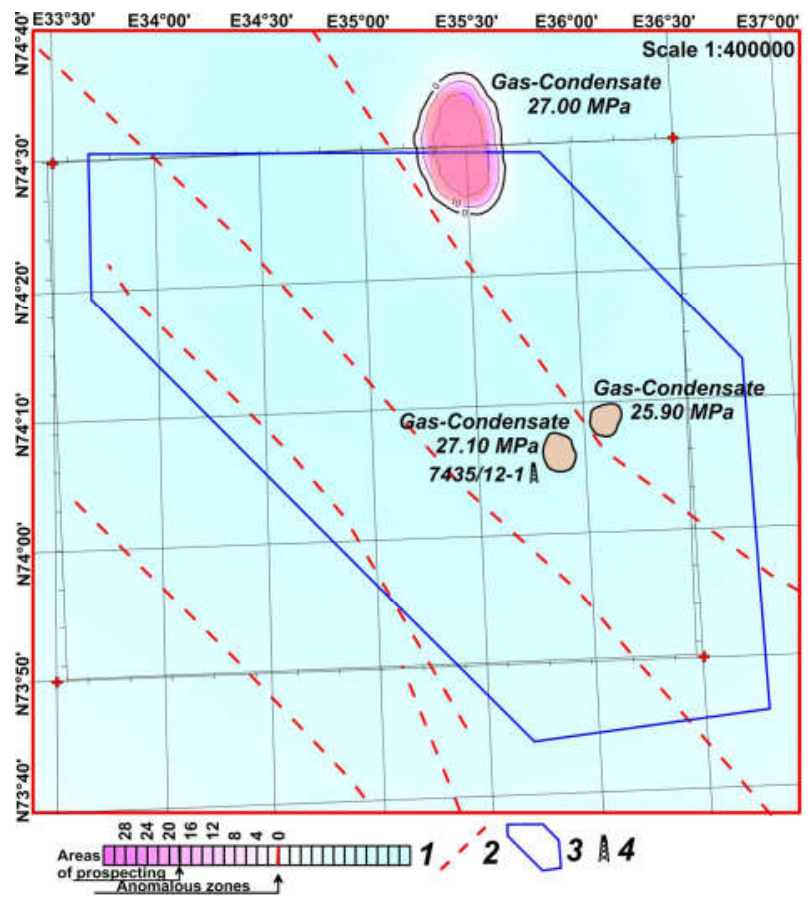

Рис. 1. Карта аномальных зон типа «Газоконденсатные залежи» в Баренцевом море. 1 - шкала значений комплексной величины пластового давления (МПа); 2 - тектонические нарушения (по результатам обработки снимков); 3 - контуры поискового блока 4 (участка проведения сейсмических исследований); 4 - примерное положение пробуренной скважины 7435/12; координаты: 7404'18.12"N, 3548'30.96" Е. (Обработка локального участка расположения пробуренной скважины - январь 2018 г.) 


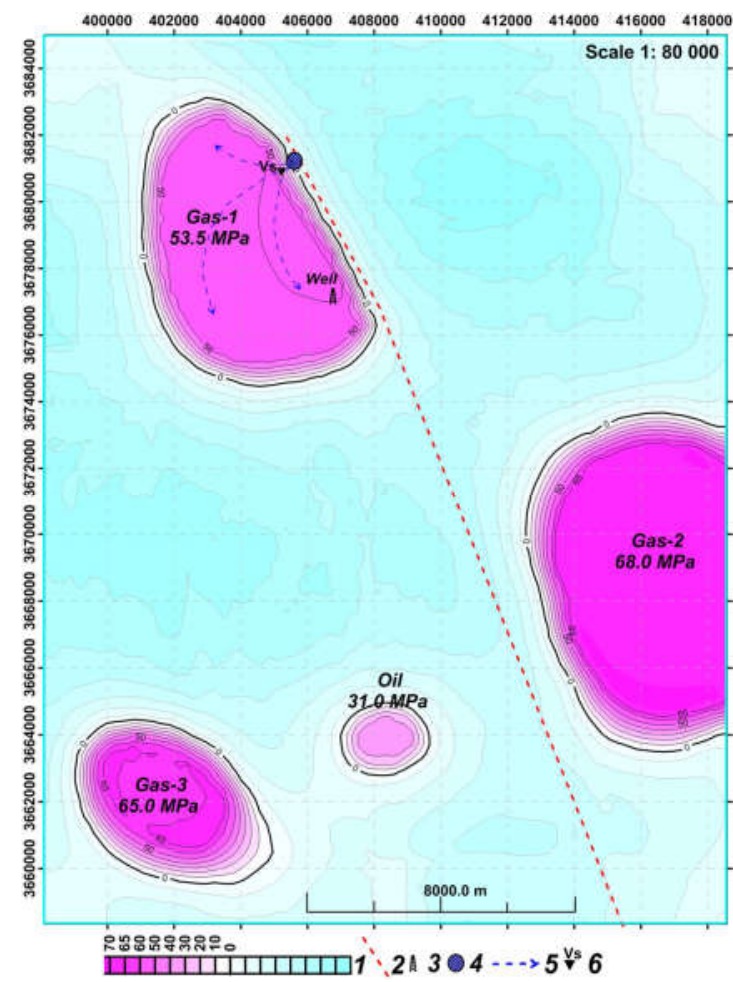

Рис. 2. Карта аномальных зон типа «Gas-Oil» на участке бурения поисковой скважины «Onisiforos

West 1» в Средиземном море (Блок 11 на шельфе Кипра). 1 - шкала максимальных значений пластового давления, МПа; 2 - тектоническое нарушение; 3 - положение поисковой скважины «Onisiforos West 1»; 4 - вертикальный канал миграции газа: координаты: X=3681141.20, Y= 405538.18; 5 - пути миграции газа.

На начальном этапе, на обследованном участке выявлена зона тектонического нарушения северо-северо-западного простирания. В районе расположения скважины закартирована аномальная зона «Gas-1», которая примыкает к разломной зоне с запада.

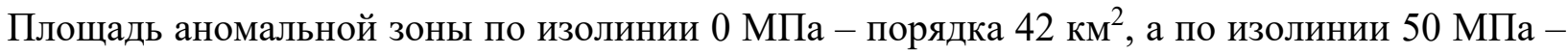

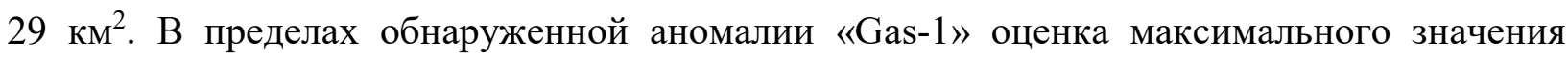
пластового давления составила 53.5 МПа. В контуре аномалии, в интервале глубин 17006000 м зарегистрированы аномальные отклики в следующих интервалах давлений (МПа): 1) 18.50 - 22.90; 2) 27.22 - 28.30; 3) 37.89 - 39.30; 4) 42.8-43.70; 5) 51.36 - 53.95.

С использованием методики обнаружения и локализации каналов вертикальной миграции глубинных флюидов [5] в районе аномальной зоны «Gas-1» такой канал был обнаружен в разломной зоне (рис. 2). Оценка значений пластового давления в центральной точке канала составила порядка 80 МПа.

В районе расположения поисковой скважины в интервале глубин 1700-6000 м выполнено сканирование геологического разреза с целью определения глубин залегания и мощностей аномально поляризованных пластов (АПП) типа «газ». По результатам 
Труды Международной конференции «Дегазация Земли: геология и экология - 2018»

сканирования в разрезе выделено семь АПП типа «газ», перспективных на обнаружение залежей газа. Наиболее перспективными на обнаружение газа являются поисковые интервалы: 1) 1800-2250 м и 2) 4050-4250 м.

Оценивая полученные материалы авторы констатировали, что результаты оперативных исследований рекогносцировочного характера повышают, в целом, вероятность обнаружения в скважине «Onisiforos West-1» залежей газа. Однако минимальный объем выполненных исследований не позволил авторам однозначно сделать вывод о том, будут ли эти скопления в коммерческих объемах, или нет.

По результатам бурения в скважине выявлены некоммерческие объемы газа.

\section{Скважины «Полшков-1» и «Рубин-1» в Черном море}

Апробация частотно-резонансной технологии обработки спутниковых проводилась в различных частях Черного моря, в том числе и в пределах лицензионных блоков Хан Аспарух и Силистар в экономической зоне Болгарии.

Исследования в районе бурения поисковой скважины «Полшков-1» на блоке Хан Аспарух проведены в мае 2016 г. В результате проведенной частотно-резонансной обработки снимка в районе бурения скважины обнаружена и закартирована аномальная

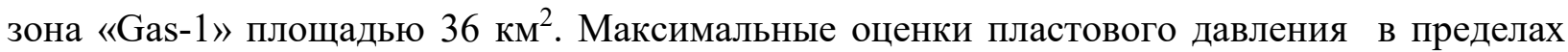
аномалии составили 62.1 МПа (рис. 3). Обратим внимание на то, что скважина «Полшков1» расположена практически в центре закартированной аномальной зоны.

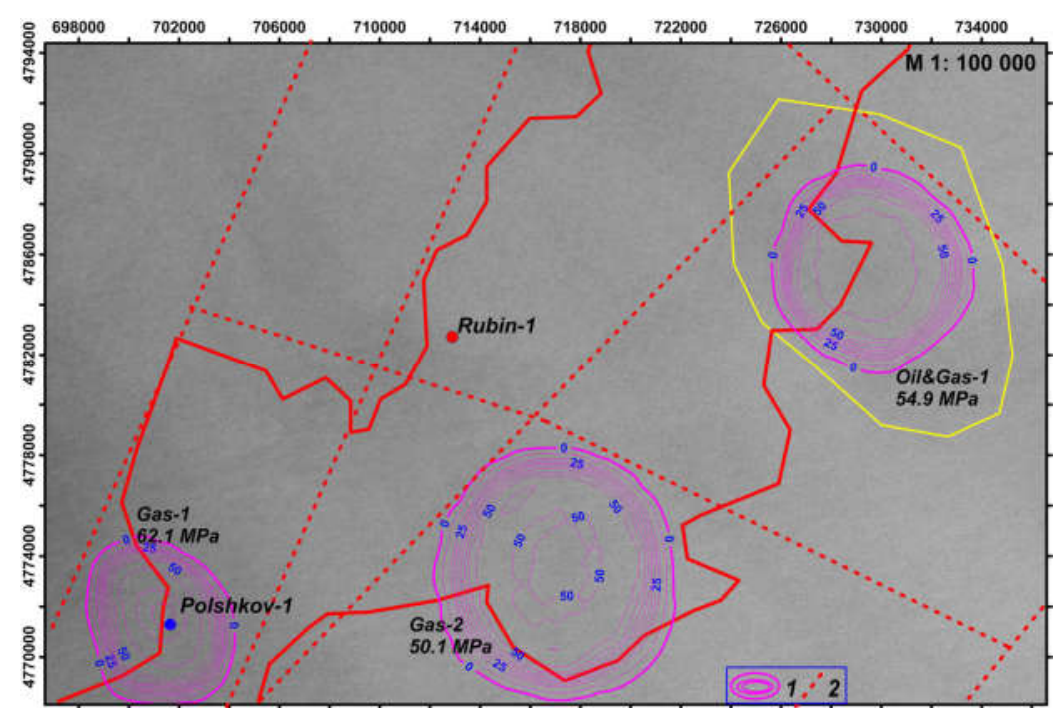

Рис. 3. Карта аномальных зон типа «Gas» и «Oil» на спутниковом снимке участка бурения поисковых скважин «Полшков-1» и «Rubin-1» в пределах лицензионного блока Хан Аспарух на шельфе Болгарии. Масштаб обработки снимка - 1:100000. 1 - изолинии максимальных значений пластового давления, МПа; 2 - зоны тектонических нарушений по результатам обработки снимка. 
Труды Международной конференции «Дегазация Земли: геология и экология - 2018»

Исследования на локальном участке бурения скважины «Рубин-1» выполнены 10 октября 2017 г. В процессе частотно-резонансной обработки снимка локального участка расположения скважины «Рубин-1» (рис. 3) аномальные отклики на резонансных частотах нефти, газа и газоконденсата, которые традиционно используются при обработке спутниковых снимков, не обнаружены. Это позволяет авторам сделать вывод, что промышленные (коммерческие) притоки углеводородов в скважине Рубин-1 не будут получены после завершения ее бурения.

По обнародованной информации в скважине «Полшков-1» обнаружены нефть и газ. Сведений о результатах бурения скважины «Рубин-1» на данный момент нет.

\section{Скважина 34/8-19 S в Северном море}

17 марта 2018 г. спутниковый снимок участка расположения проектной скважины был обработан в крупном масштабе 1:10000 (рис. 4). На обследованном участке обнаружена аномальная зона типа «газ+конденсат» с максимальными значениями пластового давления 21.3 МПа (рис. 4). В центральной части аномалии зафиксированы также аномальные отклики на резонансных частотах нефти.

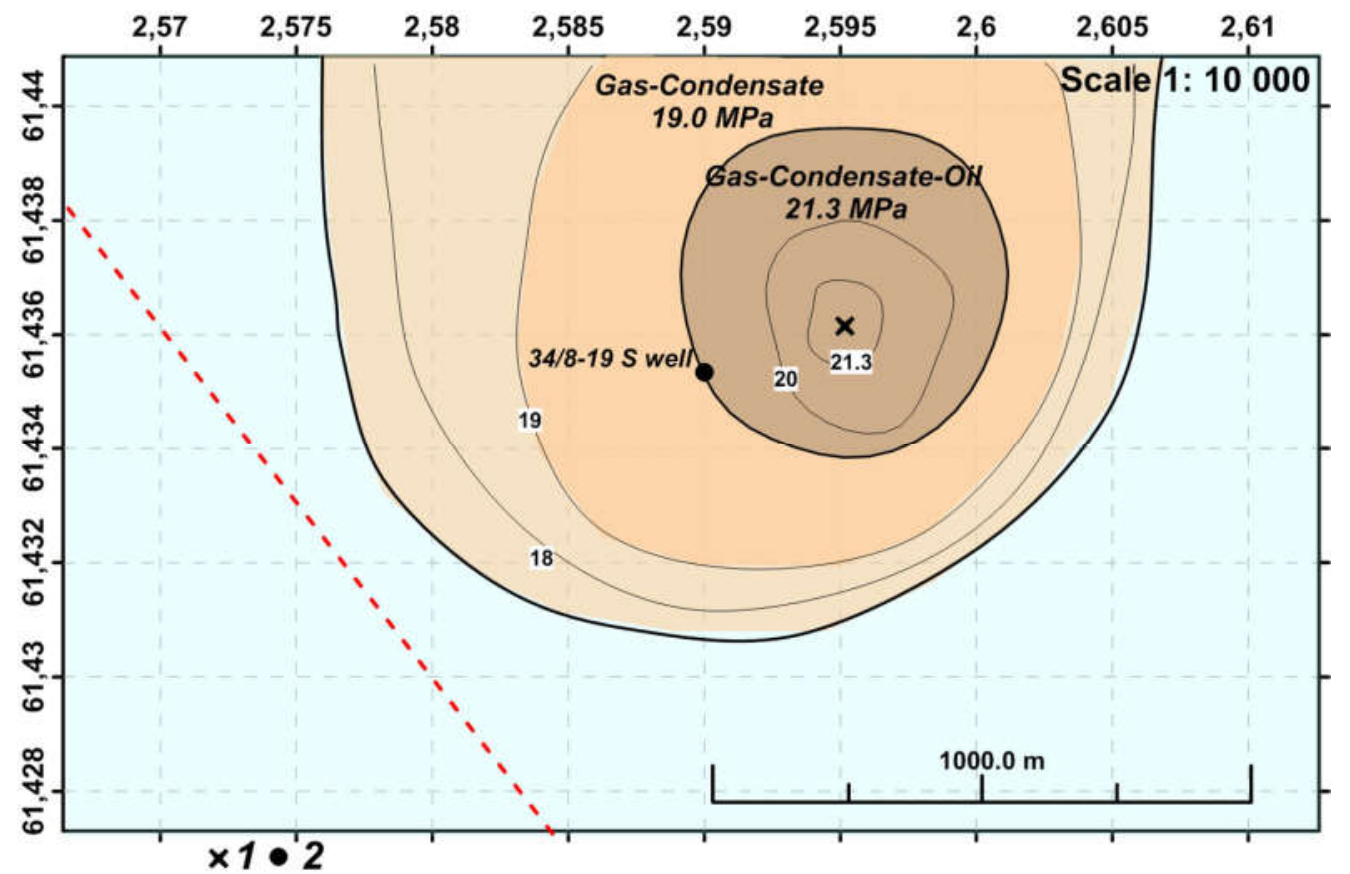

Рис. 4. Карта аномальной зоны типа «газ+конденсат+нефть» на локальном участке в районе проектной скважины 34/8-19 S в Северном море (по данным частотно-резонансной обработки спутникового снимка). 1 - центральная точка аномальной зоны, координаты: N $61.4361498^{\circ}, \mathrm{E}$ $2.595223^{\circ} ; 2$ - положение скважины 34/8-19 S, координаты: N 61²6'6.84" и Е 2³5'24.37". 
Актуальные проблемы нефти и газа • Вып. 4(23) 2018 • http://oilgasjournal.ru

Труды Международной конференции «Дегазация Земли: геология и экология - 2018»

По результатам частотно-резонансной обработки спутникового снимка наиболее оптимальным местом расположения проектной скважины 34/8-19 S можно считать центральную точку обнаруженной аномальной зоны с координатами N $61.4361498^{\circ}, \mathrm{E}$ $2.595223^{\circ}$.

\section{Выводы}

Приведенные выше результаты оценки перспектив нефтегазоносности участков бурения скважин с использованием метода частотно-резонансной обработки и декодирования данных ДЗ3 (спутниковых снимков) в очередной раз демонстрируют целесообразность более широкого применения мобильных прямопоисковых технологий в геологоразведочном процессе на нефть и газ, в том числе и на этапах выбора оптимальных мест для заложения поисковых и разведочных скважин.

В последнее время в процессе проведения исследований с использованием частотно-резонансного метода обработки спутниковых снимков начала активно применяться процедура вертикального сканирования геологического разреза. Эта методика позволяет оценивать глубины залегания и мощности АПП типа «залежь УВ», а также пластовые давления в отдельных АПП. Методика сканирования применялась при проведении исследований в районе пробуренной скважины «Onisiforos West-1».

Практически на всех участках обследования проводились поиски каналов вертикальной миграции глубинных флюидов с использованием разработанной и апробированной методики, описанной в [5]. Такие каналы (локальные участки с очень высокими значениями пластового давления) обнаружено в пределах многих закартированных аномальных зон [5], в том числе и на участке бурения скважины «Onisiforos West-1». Согласно [1], в скважинах, пробуренных в окрестностях каналов миграции могут быть получены повышенные притоки углеводородов. С другой стороны, каналы вертикальной миграции являются весомым аргументом в пользу глубинного (эндогенного) синтеза УВ в рамках глобального процесса водородной дегазации Земли.

Приведенные результаты исследований демонстрируют работоспособность и эффективность прямопоисковой технологии частотно-резонансной обработки спутниковых снимков при поисках скоплений УВ в акваториях шельфа. Более активное применение этой технологии в комплексе с традиционными геофизическими методами (сейсмическим, в первую очередь) позволит ускорить и оптимизировать геологоразведочный процесс на нефть и газ в морских акваториях и на суше. 
Труды Международной конференции «Дегазация Земли: геология и экология - 2018»

\section{ЛИТЕРАТУРА}

1. Бембель Р. М., Мегеря В. М., Бембель С. Р. Геосолитоны: функциональная система Земли, концепция разведки и разработки месторождений углеводородов. Тюмень: Вектор Бук, 2003. 344 с.

2. Левашов С.П., Якимчук Н.А., Корчагин И.Н. Новые возможности оперативной оценки перспектив нефтегазоносности разведочных площадей, труднодоступных и удаленных территорий, лицензионных блоков. Геоінформатика. 2010. № 3. C. 22-43.

3. Левашов С.П., Якимчук Н.А., Корчагин И.Н. Оценка относительных значений пластового давления флюидов в коллекторах: результаты проведенных экспериментов и перспективы практического применения. Геоінформатика. 2011. № 2. С. $19-35$.

4. Левашов С.П., Якимчук Н.А., Корчагин И.Н. Частотно-резонансный принцип, мобильная геоэлектрическая технология: новая парадигма геофизических исследований. Геофизический журнал. 2012. Т. 34, № 4. С. 167-176.

5. Levashov, S.P., Yakymchuk, N.A., Korchagin, I.N. and Bozhezha, D.N., (2017a), Application of mobile and direct-prospecting technology of remote sensing data frequencyresonance processing for the vertical channels of deep fluids migration detection. NCGT Journal, v. 5, no. 1, March 2017, p. 48-91. www.ncgt.org

6. Yakymchuk N.A., Levashov S.P., Korchagin I.N., Bozhezha D.N. Mobile Technology of Frequency-Resonance Processing and Interpretation of Remote Sensing Data: The Results of Application in Different Region of Barents Sea [Электронный ресурс]. Offshore Technology Conference Arctic Technology Conference, 23-25 March, Copenhagen, Denmark, 2015. - DOI:10.4043/25578-MS. -https://www.onepetro.org/conference-paper/OTC-25578-MS. 